Retraction

\title{
Retracted: The Impact of Graft Nephrectomy on Subsequent Transplants: Multivariate Analysis of Risk Factors for Second Graft Loss and for Multiple Transplantations-A Single-Center Retrospective Study
}

\author{
International Scholarly Research Notices \\ Received 26 September 2016; Accepted 26 September 2016 \\ Copyright (c) 2016 International Scholarly Research Notices. This is an open access article distributed under the Creative Commons \\ Attribution License, which permits unrestricted use, distribution, and reproduction in any medium, provided the original work is \\ properly cited.
}

At the request of the authors and the hospital, the article titled "The Impact of Graft Nephrectomy on Subsequent Transplants: Multivariate Analysis of Risk Factors for Second Graft Loss and for Multiple Transplantations-A Single-Center Retrospective Study" [1] has been retracted. The data reported in the article were not reviewed by the Renal Transplant Unit of the Royal London Hospital before submission. The data is not a complete capture and as a result is not an accurate reflection of the effect of the intervention.

\section{References}

[1] E. Giorgakis, A. Syed, and H. Gonzalez, “The impact of graft nephrectomy on subsequent transplants: multivariate analysis of risk factors for second graft loss and for multiple transplantations-A Single-Center Retrospective Study," ISRN Transplantation, vol. 2013, Article ID 362571, 9 pages, 2013. 